\title{
The Mother Tongue of Turkish Immigrant Children in Berlin: To Be or Not to Be?
}

\author{
Hristo Kyuchukov \\ University of Silesia
}

\begin{abstract}
Correspondence concerning this article should be addressed to Hristo Kyuchukov, University of Silesia, Bankowa 12, 40-007 Katowice, Poland.E-mail: hkyuchukov@gmail.com
\end{abstract}

\begin{abstract}
How do bilingual Turkish children develop their mother tongue knowledge in German kindergartens and what are some of the difficulties they face? These are the questions which this paper tries to answer. For this purpose, a study with Turkish kindergarten children from Berlin, Germany was conducted.

A total of 40 children were divided into two groups between 3 and 6 years old and tested twice in a year with the TEDIL Test ${ }^{1}$. The test consists of pictures and measures the knowledge of Turkish nouns, verbs, adjectives, prepositions, and syntax. All of the children were tested individually by a native Turkish speaker and by the researcher. The testing was done in the kindergarten setting.

The results showed that the knowledge of both age groups on different grammatical categories in Turkish was equal on the first test and there were no statistical differences. However, during the second test the group of older children showed a decrease in their knowledge of the grammatical categories in their mother tongue. This paper discusses the factors that influenced the regression in the knowledge of Turkish.

This study is one of only a few on bilingual Turkish children and it presents new information about mother tongue loss among kindergarten children, discusses the reasons, and suggests that kindergartens and families should cooperate and work together in order to prevent mother tongue loss from a very early age as well as its effect on the cognitive development of bilingual children.
\end{abstract}

Keywords: Turkish, mother tongue, kindergarten, language loss

Turkish spoken in Germany and one of the migrant languages has a low status in German society. Although there are kindergartens and schools where Turkish is taught a few lessons per week and there are published journals, newspapers, and radio programs, still Turkish, together with other migrant languages such as Russian and Arabic, has not been accepted in German society (Giray, 2015). An adequate level of acquisition of German the official language still seems to be a huge obstacle for most Turkishspeaking children living in Berlin. Several theories try to explain the reasons for this situation, which is not only a problem in Germany. In this work I will focus on the mother tongue and its importance for acquiring and learning further languages, especially the official language of the host country.

Turkish mother-tongue education in Berlin kindergartens has not been integrated into the

\footnotetext{
Güven, S., \& Topbaș, S. (2014). Türkçe erken dil gelişimi testi (TEDÍL) [Turkish early language development test]. Ankara, Turkey: Psychology Press.
}

regular curriculum. Moreover, there are no pre-school structured options for children to develop their use of and proficiency in their home language (NIER, 2018). The kindergartens do not value Turkish in the learning contexts, although there is a large Turkish community in Berlin. When there are offerings of Turkish courses decided upon individually by the kindergartens themselves, then the number of lessons and pedagogical quality are generally limited. There is no idea or conception regarding the mother tongue as a resource for attaining better competence in the second language, a solid foundation for a child's overall literacy, self-confidence, and cognitive development ${ }^{2}$ (Mongeau, 2018; NIER, 2018).

The present paper discusses this situation and presents the findings of a research project with

\footnotetext{
Rutgers Today. (2018, May 26). New pre-k report finds state policy for young dual language learners needs improvement. Rutgers Today. Retrieved from https://news.rutgers.edu/new-pre-k-report-finds-state-policy-young-dual-language-learners-needsimprovement/20180418\#.WwzugNR94sY
} 
Turkish children who are in effect DLLs (duallanguage learners) conducted 2016-17 in two Berlin kindergartens in different districts on the city with substantial Turkish immigrant populations (Wedding \& Neukölln). The children in the study come largely from middle-class families in terms of socio-economic status (SES). Their parents in most cases try to speak with the children in German only, thinking that in this way they help them to be better prepared for school. But the German of their parents very often is substandard spoken German. They make typical errors in case markers and especially in the noun category (i.e. gender), aspects of German morphology, and lexis that is difficult to learn. Moreover, children in the kindergartens do not obtain permission from the teachers to speak Turkish among themselves. In most cases the teachers are also from a Turkish background but have been instructed not to allow the children to use their mother tongue even at play at school or in different activities. Teachers have not been trained to encourage DLLs to develop literacy both in their L1 and in German (NIER, 201; Mehmedbegovic, 2009).

The attitude of society towards a minority/ migrant/refugee language is an important factor for the language development of young children. This attitude consciously or unconsciously can motivate or demotivate the children from learning their mother tongue and building positive or negative attitudes towards their own mother tongue, and a kind of subliminal "linguicism" at work has been institutionalized (Skuttnabb-Kangas, 1995; Templer, 2016). Mehmedbegovic (2009), from a Bosnian immigrant background, stresses that for young learner education in the UK, this needs to be struggled against and policies must be changed, underscoring the priority of recognizing and fighting against the domination of the cultural capital of certain elites as "symbolic violence" in Bourdieu's sense, where dominated groups "accept a social construct like marginalization of first languages as a necessity of the same order as the law of gravity" (p. 250).

Considering multilingual children, it is important not to lose sight of the influential role of their mother tongue. It has an impact on the social and personal development of the child (Cummins, 2001, p. 17), and also on a learner's cognitive development (Cummins, 2009). Children who gain an adequate mother-tongue education or sufficient mother-tongue language input in their early childhood "develop stronger literacy abilities" in the school language (Cummins, 2001, p. 17). But it is not just important to provide a mothertongue education or bilingual learning programs in the kindergarten, it is also significant to support and "advise parents and other caregivers to spend time with their children and tell stories or discuss issues with them" which are preconditions preparing the children for learning the school language and being successful in their educational way (Cummins, 2001, p. 17). Cummins stresses that two languages are "interdependent and nurture each other when the educational environment creates the requirements" for the children. "Well-implemented bilingual programs can promote literacy and subject matter knowledge in a minority language without any negative effects on children's development in the majority language." Learning the home language (minority language) not only impacts the cultural and personal identification, which makes it easier for learners to identify "with the mainstream culture and learning the mainstream language" (Cummins, 2001, p. 16), it also helps with "learning concepts and intellectual skills that are equally relevant to their ability to function in the majority language" (Cummins, 2001, p. 18). Developing literacy in both or more languages enables the children to "compare and contrast two language systems," meaning that they have access to more solidly grounded reality interpretations (Cummins, 2001, p. 17). Bilingual children quickly acquire conversational skills in the majority language (Cummins, 2001, p. 19; Vivian, 2015; Kroll \& Bialystok, 2013) and can easily and quickly participate in the majority society.

There are "[S]trong affirmative messages about value of knowing additional languages and the fact that bilingualism is an important linguistic and intellectual accomplishment" (Cummins, 2001, p. 19; Cummins, 2009). For example, children then develop the ability to obtain access to information via a range of sources in different languages. The preschool years are important not just for socialization and the development of personality and character; this period also includes the critical phase that is important for the foundation of mother-tongue skills, providing a basis for future success not just for adequate competence in the home language but also for second-language acquisition and other languages that may be acquired or later studied (NIER, 2018; Mongeau, 2018). In data from the UK, Mehmedbegovic (2009) discusses equality issues for children with skills in languages other than English in the schools in England and Wales with recommendations for policy and teacher training, changing the school ethos toward a "culture of recognizing an all-encompassing communication competence developed by the use of different languages" (p. 243).

According to Yazici, Ilter, \& Glover (2010) there is a relation between mother-tongue competence and reading readiness. A rich lexicon in the mother tongue facilitates easier literacy achievement (Yazici, 1999). But to benefit fully from education in the second language, providing more opportunities for using the mother tongue has to be the aim in order to raise levels of mother-tongue competence. Benson (2002, 
p. 303), looking at the effects of bilingual education in Africa and Latin America, notes that "Use of the mother tongue in primary schooling offers a number of documented benefits such as valorizing the mother tongue, bridging the gap between home and school cultures, and raising student identity consciousness and self-esteem." Benson ${ }^{3}$ also notes: "Transfer of linguistic and cognitive skills is facilitated in bilingual programs. Once students have basic literacy skills in the L1 and communicative skills in the L2, they can begin reading and writing in the L2, efficiently transferring the literacy skills they have acquired in the familiar language. [...] Mother tongue-based bilingual education not only increases access to skills but also raises the quality of basic education by facilitating classroom interaction and integration of prior knowledge and experiences with new learning."

Citing Cummins (2001), Ileri (2000) and Saracho (1983), Yazici et al. (2010) argue that pre-school children should use their mother tongue, a foundation for developing literacy that is needed to support the second language both at home in school and in social interactions in the broader society. This is also strongly stressed by research findings in the US (NIER, 2018; Mongeau, 2018). Parents should help their children improve their native language skills. They should acquire picture books and other children's books in the L1 in order to build up a basis for a child to read and learn to love to read in the home language. Local libraries need to build up collections of such books for young learners in languages widely spoken by migrants living and attending schools in a given neighborhood. Findings also reflect the negative effects on self-esteem, which may lead to disharmony between the school and home cultures ${ }^{4}$. Parental reports can exaggerate the amount of mother-tongue use, as noted by Tannenbaum (2003), so the figures may show a higher level of mother tongue use than is actually the case. Empirical ethnographic research is needed to establish the actual realities of such L1 use and a child's competency in the L1.

\section{The Role of the Mother Tongue in the Development of Bilingualism among Children}

De Houwer (2011) argues that many of the differences between individual bilingual children's use of their two languages can be attributed to differences in the language input environments for each of the languages. These language input environments concern, amongst others, language use patterns in

\footnotetext{
3 Benson, C. J. (2004). The importance of mother-tongue based schooling for educational quality. UNESCO, EFA Global Montoring Report 2005. P. 17. Retrieved from http://unesdoc.unesco.org/images/0014/001466/146632e.pdf

4 Ibid.
}

the parent pair, the age of first regular exposure to each language, relative and absolute frequencies of input for each language, and interaction strategies. If indeed it is the case that differences in language input environments can explain much of the variation between one child's use of two languages (and, by extension, inter-individual variation between bilingual children), this has important repercussions for the assessment of bilingual children in school and elsewhere. Dixon, Zhao, Quiroz, \& Shin (2012) investigate the influence of home and community factors in predicting ethnic or heritage language vocabulary of Singaporean children whose ethnic languages (or mother tongues) were Chinese, Malay, or Tamil, and who were also learning English. The results indicated that (1) parents speaking an ethnic language to children had a strong positive effect on children's ethnic language vocabulary, whereas parents speaking only English had a negative effect; (2) the language community had an effect on children's ethnic language vocabulary, which may reflect community support for the language among the broader community; (3) family income worked differently depending on the language community; and (4) watching television in English mostly/only had a negative effect on children's ethnic language vocabulary. These findings lend support to other studies among language-minority children indicating that maintaining an ethnic or heritage language requires home support when schooling is through a societally dominant language.

Another study by Becker, Klein, \& Biedinger (2013) analyzes the longitudinal development of differences in academic skills between children of Turkish origin and children of native-born German parents from age 3 to 6 in Germany with a focus on the role of immigrant parents' acculturation to the receiving society. Growth curve models show that Turkish-origin children start with lower test scores at the age of 3 regarding German language skills and cultural knowledge but not with respect to cognitive skills. The difference in the language domain decreases until the age of 6 , while it increases regarding children's cultural knowledge. Immigrant parents' acculturation to the receiving country is positively related with all three academic skill domains. The results point to the importance of early intervention strategies.

The home environment, the language input by the parents and family members, and a positive attitude of the society towards the minority language are extremely important factors for the development of the mother tongue of bilingual children.

\section{The Berlin Study}

An empirical investigation was conducted by the author in 2016-17 among 40 Turkish children 3 to 6 
years old attending two kindergartens in Berlin (in the districts of Wedding and Neukölln). There are kindergartens in Berlin that usually have children from age 2 until age 6 . They have the freedom to choose the curriculum, methods of teaching, teachers, and textbooks. There are kindergartens where only German is used as the language of instruction, but there are also bilingual kindergartens such as RussianGerman, English-German, or Spanish-German; however, there are no Turkish-German kindergartens where both languages are used half-half in everyday activities with children. In some kindergartens with predominantly Turkish children, there are once-aweek lessons in Turkish as a mother tongue, but this is not in all kindergartens with Turkish children.

The goal of the study was to determine key aspects of the linguistic knowledge of children whose mother tongue was Turkish. They were tested twice in their L1 home language in November 2016 and June 2017. The children from the two kindergartens from two different parts of Berlin had one-hour lessons in Turkish with a Turkish language teacher once a week.

\section{Research Questions and Hypotheses}

The study has the following research questions:

1. Which grammatical categories did the children know when Turkish was their L1?

2. How much did the knowledge of grammatical categories in the L1 increase between the first and second testing considering the children's age?

\section{Hypothesis}

The lessons in Turkish, which the children had in the kindergartens, would help them increase their knowledge of their L1 (Turkish).

\section{Materials and Methods}

\section{Participants}

Two groups of children were tested twice. The age of the children between first and second testing differed by 6-7 months. The age of the children during the first testing was:

Group 1: 3 years, 6 months to 4 years, 5 month of age - 20 children (10 from each kindergarten)

Group 2: 4 years, 6 months to 5 years, 6 months of age - 20 children (10 from each kindergarten)
The kindergartens did not differ. Both have children from mixed ethnic backgrounds, but the number of Turkish speaking children was high. The kindergartens were selected based on the fact if they offer organized lessens in Turkish as an L1. Both kindergartens have Turkish mother-tongue teachers and Turkish lessons are given once in a week to the children.

The children included in the study were selected according to three criteria:

- to speak Turkish as their mother tongue;

- to be in the age range between 3 and 6 years old;

- to be normally developing children without any delays or disabilities.

All the children were born in Germany and they knew German as well. Most of the parents of the children were also born in Germany, but some of them - very few, were born in Turkey and came to Germany as children. The socio-economic status of the families was low. Most of the parents had completed secondary school education in Germany. In their home environment, according to self-reports from the parents, most of them spoke mixed German-Turkish with their children.

\section{Materials}

The children in the study were tested with a test adapted from English and standardized for Turkish: "Test of Early Language Development - Third Edition $(\text { TELD-3 })^{5}$. The test has two parts - comprehension and production of different grammatical categories: nouns, verbs, adjectives, preposition, syntax (comprehension and creating sentences with given words), and the comprehension and production of narratives.

The test is a booklet with colorful pictures, and each page has a picture. Here are some examples from the test.

\section{Nouns}



Güven, S., \& Topbaș, S. (2014). Türkçe erken dil gelişimi testi (TEDÍL) [Turkish early language development test]. Ankara, Turkey: Psychology Press. 


\section{HRISTO KYUCHUKOV}

Verbs

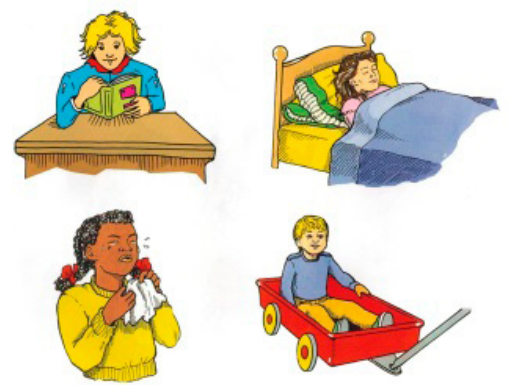

Prepositions

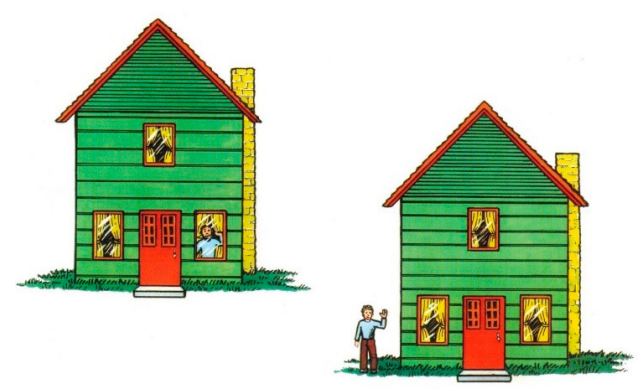

\section{Procedure}

Each child was tested in a separate room where the researcher and a teacher were present. The testing with each child took between 15 and 20 minutes. The children's answers were partly audio recorded and partly filled in on a paper form. For each correct answer the child got 1 point and for a wrong answer -0 points.

\section{Analysis}

The results of the children were coded and analyzed with ANOVA.

\section{Results}

\section{First Testing}

Comprehension Test. In the first test on comprehension, the children from both locations showed similar results. Both age groups had the same understanding of the tasks and there were no statistically significant differences in the level of understanding of the grammatical categories. In the domain of Turkish morphology, children were examined for their understanding of nouns, adjectives, verbs, and prepositions, and in syntax they had to understand the sentences and text in their mother tongue. This is shown in Table 1.
The Table shows that the values of F-criteria and $\mathrm{p}$ for all factors and all kind of interactions are very low. That means that none of the three factors (gender, location, and age group) and their interactions are statistically significant for the total score of the comprehension test. This indicates that the children from both age groups understood all of the grammatical and syntactic categories equally well.

Production Test. However, there were statistically significant differences in production. Both age groups of children from the first location, Wedding, showed similar results in production and there were no statistically significant differences in their knowledge. However, the results of the children from the second location, Neukölln, showed that there were statistically significant differences for both age groups. The next figure shows the total scores of the production test as a function of the independent factor "location."

Figure 1 shows that the children from Wedding were much better in production, i.e. they knew the grammatical categories in Turkish much better than the children from Neukölln. The differences are statistically significant $F(1,32)=6,6258$ and $p=.01488$ $(\mathrm{p}<0.05)$.

If we compare the results of the children by age group and location we see that these two factors mutually interact, as displayed in Figure 2.

There were no statistically significant differences in the production of the children from the first and second age group from Wedding. In this location the knowledge of the children regarding grammatical categories of Turkish morphology and syntax was similar. However, this was not the case with the children tested in Neukölln. There were statistically significant differences between the two age groups. The children comprising the older group produced all grammatical categories much better then the younger children ( $F$ $(1,32)=5,6113, p=.02405(p<0.05)$. There were also differences between the younger group of children (3;6 - 4;5 years old) from both locations. The children from Wedding were much better in production than the children from Neukölln. There were no statistical differences in producing the grammatical categories between the children in the older group $(4 ; 6-5 ; 6$ years old). The children from both locations knew the categories equally well.

Figure 2 shows that there were no differences between the total scores of both age groups in Wedding regarding the factor "location," but there were significant differences in the total scores of both groups from Neukölln ( 8,2 for $4 ; 6-5 ; 6$ years old and 6,2 for $3 ; 6-4 ; 5$ years old. The other factors did not influence the results statistically. These can be seen in the next Table 2, where the values of F- criteria and $\mathrm{p}$ are given. 
Table 1

Total scores on the comprehension test

\begin{tabular}{lccccc}
\hline & $\mathbf{F}$ & $\mathbf{p}$ & Partial eta-squared & Non-centrality & Observed power (alpha=0,05) \\
\hline Intercept & 730,7462 & 0,000000 & 0,958046 & 730,7462 & 1,000000 \\
Location & 0,1240 & 0,727022 & 0,003861 & 0,1240 & 0,063482 \\
Gender & 1,0003 & 0,324740 & 0,030312 & 1,0003 & 0,162875 \\
Age group & 3,5101 & 0,070153 & 0,098848 & 3,5101 & 0,443334 \\
Location*Gender & 0,1240 & 0,727022 & 0,003861 & 0,1240 & 0,063482 \\
Location*Age group & 0,7384 & 0,396574 & 0,022554 & 0,7384 & 0,132636 \\
Gender*Age group & 0,0335 & 0,855854 & 0,001047 & 0,0335 & 0,053625 \\
Location*Gender*Age group & 0,0335 & 0,855854 & 0,001047 & 0,0335 & 0,053625 \\
\hline
\end{tabular}

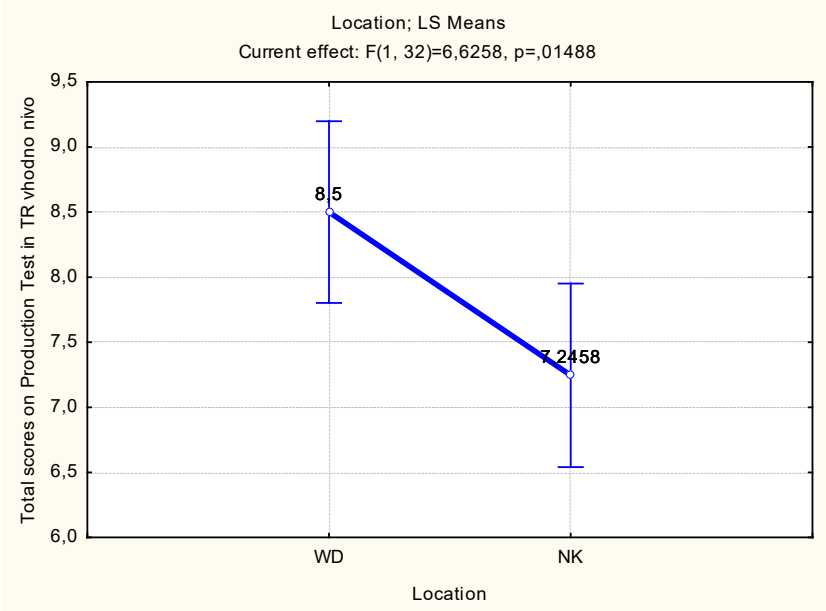

Figure 1. Total scores on the production test as a function of the independent factor "location".

\section{Second Testing}

Comprehension Test. At the end of the school year, the children were tested once more. Between the first and second testing there was a time span of 6-7 months. The results are shown in Table 3.

From Table 3, the factor with significant differences on the comprehension test is the age group. However, there were no gender differences between the children taking this test. This can be seen clearly in Figure 3 .

The children from the second age group (4;7-6;0 years old) were much better on the comprehension test than the children from the first age group $(3 ; 0-4 ; 6$ years old). With the increase in the age of the children, their comprehension abilities increased as well. The differences between the groups are statistically different $F(1,35)=13,889 ; \mathrm{p}=.00068(\mathrm{p}<.001)$.

Production Test. The results in the production test are presented in Table 4.

Again the significant factor here is the age group.

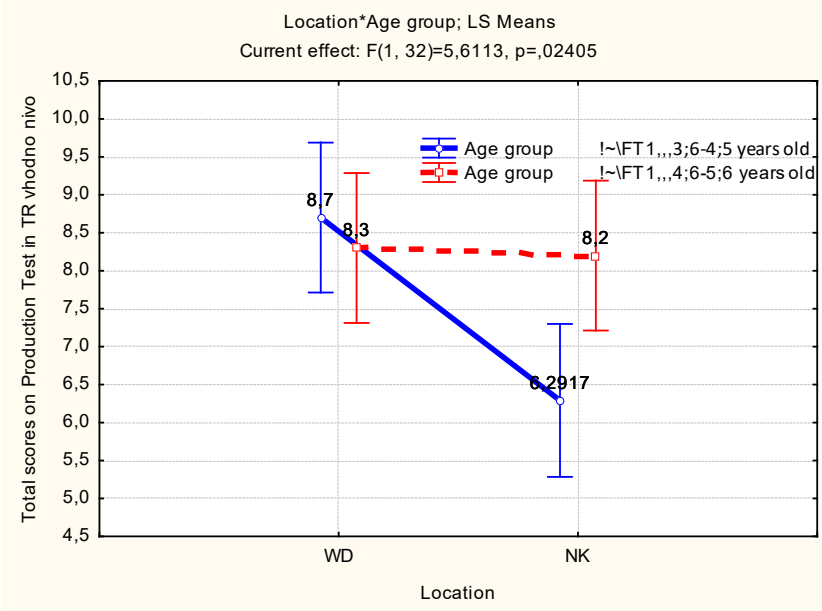

Figure 2. Total scores on the production test as a function of the interaction between factors "location" and "age group".

The older children were better on the production test than the younger children. There were no gender differences between the children on the performance of this test. These differences are shown in Figure 4.

The differences between the age groups are statistically significant $F(1,35)=4,0533 ; p=.05182$, $(p<$ $0.05)$.

When we compare the results of the comprehension tests between the first and second testing, we see that age group as a factor plays an important role. The children understand more about their L1. However, when we compare the production test between the first and second testing, we see that the children's knowledge in the production test decreased. The average raw score of the children from the second group on the first testing was 8.2, and by the second testing six months later, the raw score was 6.4. The differences are statistically significant $(\mathrm{p}<0.05)$. The children's knowledge about nouns was good to some extent, but their knowledge about verbs, adjectives, and 


\section{HRISTO KYUCHUKOV}

Table 2

Total scores of the production test

\begin{tabular}{lccccc}
\hline & $\mathbf{F}$ & $\mathbf{p}$ & Partial eta-squared & Non-centrality & Observed power (alpha=0,05) \\
\hline Intercept & 1044,382 & 0,000000 & 0,970271 & 1044,382 & 1,000000 \\
Location & 6,626 & 0,014885 & 0,171538 & 6,626 & 0,704106 \\
Gender & 0,579 & 0,452169 & 0,017781 & 0,579 & 0,114433 \\
Age group & 2,396 & 0,131490 & 0,069656 & 2,396 & 0,323580 \\
Location*Gender & 0,123 & 0,728171 & 0,003827 & 0,123 & 0,063362 \\
Location*Age group & 5,611 & 0,024048 & 0,149192 & 5,611 & 0,632083 \\
Gender*Age group & 0,309 & 0,582172 & 0,009563 & 0,309 & 0,083937 \\
Location*Gender*Age group & 0,309 & 0,582172 & 0,009563 & 0,309 & 0,083937 \\
\hline
\end{tabular}

Table 3

Gender and age group on the raw scores on the comprehension test

\begin{tabular}{lccccc}
\hline & $\mathbf{F}$ & $\mathbf{P}$ & Partial eta-squared & Non-centrality & Observed power (alpha=0,05) \\
\hline Intercept & 337,2376 & 0,000000 & 0,905974 & 337,2376 & 1,000000 \\
Gender & 0,0216 & 0,884094 & 0,000616 & 0,0216 & 0,052341 \\
Age group & 13,8889 & 0,000683 & 0,284091 & 13,8889 & 0,951818 \\
Gender*Age group & 2,2866 & 0,139475 & 0,061325 & 2,2866 & 0,312644 \\
\hline
\end{tabular}

prepositions appeared to be worsening. At the same time, their ability to create sentences with given words and the production of a narrative was also very poor.

\section{Discussion}

This study showed that the children from the first and second testing knew the nouns well but as their age increased their knowledge of the verbs, prepositions, and sentence/narrative creation worsened. Unfortunately, my hypothesis that the lessons in Turkish as a mother tongue would help the children increase their knowledge of their mother tongue was not fulfilled.

The principal questions raised by the findings are: Why does the competence of the children in production decline as they grow a bit older? Why can the children not speak their Turkish L1 as well as they grow somewhat older? What are the reasons for the children not knowing their mother tongue well as they progress in school? In the kindergartens there are mother-tongue lessons once a week where a teacher comes and speaks with them in Turkish, reads books, and they are taught to sing songs in Turkish, but during the rest of the time the children are not allowed to speak Turkish. The teaching staff, some of whom are also of Turkish origin, forbid the children to speak their mother tongue and put demonstrable pressure on the children to speak German only. In addition, the teachers explain to parents that for the good of their children, they should not speak with them at home in Turkish but should try to use only German.

The probable hypothesis here is that the children growing up in such an environment start to think that their mother tongue is something negative. They unconsciously develop negative attitudes toward their L1, feeling ashamed that they speak it, and they get the impression from the teachers that if they speak German only, that will be better for them. They are being acculturated by the educational system to

Table 4

Gender and age group on the raw scores on the production test

\begin{tabular}{lccccc}
\hline & F & p & Partial eta-squared & Non-centrality & Observed power (alpha=0,05) \\
\hline Intercept & 181,4692 & 0,000000 & 0,838314 & 181,4692 & 1,000000 \\
GenderPr & 0,1501 & 0,700820 & 0,004269 & 0,1501 & 0,066423 \\
Age group Pr & 4,0533 & 0,050000 & 0,103790 & 4,0533 & 0,499231 \\
GenderPr*Age group Pr & 2,1541 & 0,151120 & 0,057977 & 2,1541 & 0,297561 \\
\hline
\end{tabular}




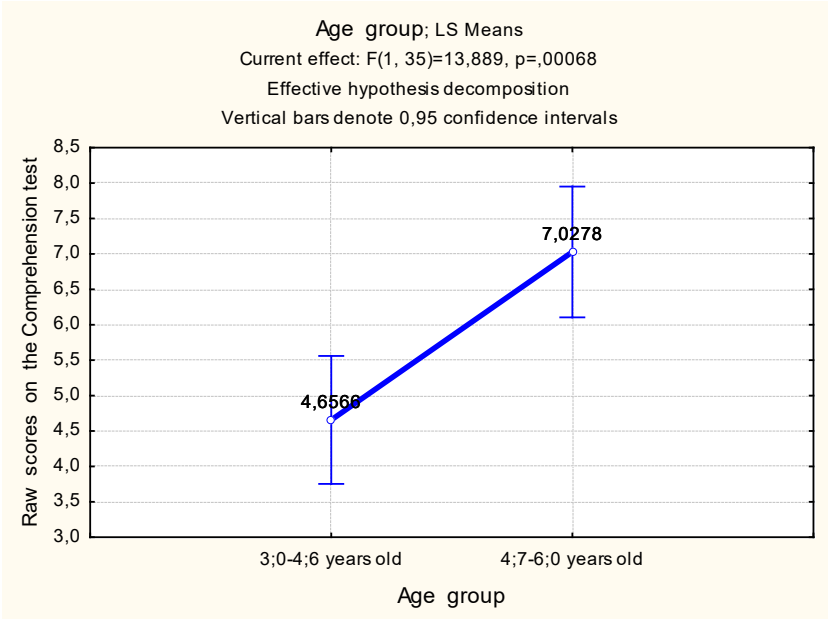

Figure 3. Raw scores on the comprehension test as a function of age group as an independent factor.

value a knowledge of German and at the same time to devalue the knowledge of their natural home language. Many of the teachers, it can be argued, do not realize the kind of deleterious impact such an approach has on the children and their development of literacy skills at this age. That is because the children speak Turkish at home in communication with their parents and grandparents but very often the parents also speak some dialect of Turkish or they speak "broken" Turkish. So the only place where the children can learn proper and correct standard Turkish is in kindergarten or at school. However, there the children do not receive proper support either. Growing up with "broken" colloquial Turkish, however defined linguistically, i.e. Turkish deviating from more standard forms, is an obstacle for better understanding and learning of the official language as well, i.e standard German. The gaps in the knowledge of the mother tongue from pre-school age constitute an obstacle for learning the grammatical categories in the second language as well (Skutnabb-Kangas, 2000; Cummins, 2001, 2009).

So are Turkish children losing their L1 growing up? According to Haynes (2010) "language loss can occur on two levels. It may be on a personal or familial level, which is often the case with immigrant communities in the United States, or the entire language may be lost when it ceases to be spoken at all." National and official languages can sometimes differ. In some cases there are countries that do not have an official language (such as the United States) but have a national language (Haynes, 2010). The use of the national language is reinforced through government and educational institutions, television and radio, and private businesses. Often the national language takes over absolute prominence at all levels of social and economic life and excludes other languages, which are minority or migrant/refugee languages. This is termed "linguicism" in international research on bilingualism.

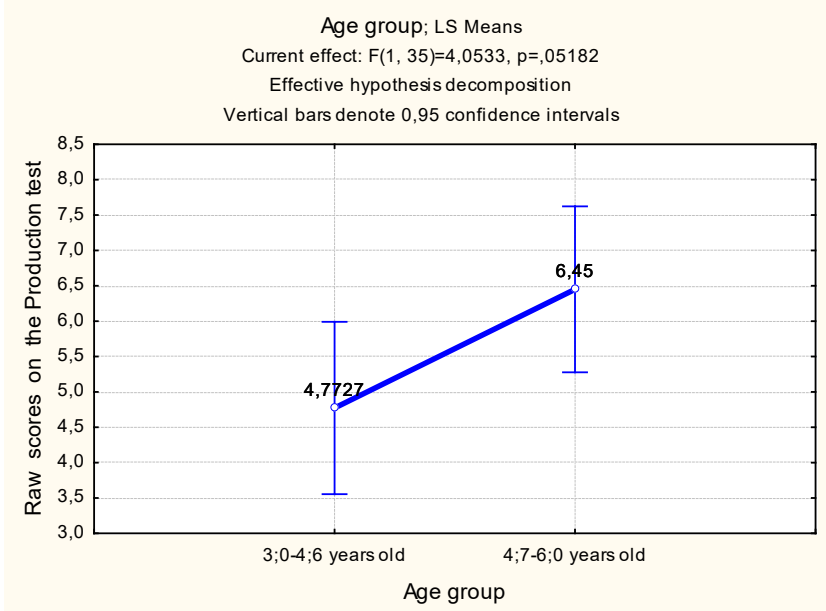

Figure 4. Raw scores on the production test as a function of age group as an independent factor.

In Skutnabb-Kangas' classic definition (1995, p. 42), linguicism is defined as "ideologies and structures that are used to legitimate, effectuate and reproduce an unequal division of power and resources (both material and non-material) between groups which are defined on the basis of language (on the basis of their mother tongues)." Templer (2016) discusses such current "linguicism" in state educational policy today directed against speakers of Turkish and Romani as a home language in Bulgaria.

MacGregor-Mendoza (2000) reports about the experiences of Spanish-speaking immigrants in US schools, where some teachers would punish them for speaking even a word of their home language. Her informants came to feel that Spanish was inappropriate or inferior (some were told explicitly that it was "dirty"), and many reported that they abandoned it when raising their own children.

Another example from the US pertains to Native American students who historically are a classic example of assimilation to English. Beginning in the late 1800 s, mandatory boarding schools were established for the purpose of eradicating Native American languages and cultures. The founder of the boarding school system, General Richard C. Pratt, is famous for saying of his schools that they would, "kill the Indian to save the man." Students were kept away from their families and communities for years and were punished, often harshly, for speaking their home languages (Child, 1998). As a result of their experiences, many Native American parents refused to teach their children their heritage languages to protect them from similar hardships. Smitherman (1995) has discussed this issue in the US and elsewhere, phrased as "students' right to their own language," a classic formulation in terms of basic educational rights (see also Templer, 2016, p. 155-156).

Another example is the case of Yiddish, in the USA, 
where English was strictly required of children by their teachers early in the 20th century, and Yiddish, the mother tongue of Eastern European Jewish immigrants was thus lost.

The situation in Europe with minorities is not different. For example, a highly authoritarian, nationalist example of assimilation was the practice initiated for supposedly "integrating" the sizable Turkish-speaking minority in socialist Bulgaria in the 1980s, where Turkish and Muslim Roma family and first names were changed by force (1984) and it was forbidden for them to speak Turkish or Romani between 1984 and 1990. The minority languages were forbidden to be used in public places and in schools. Anyone who was 'caught' even saying a single word in their mother tongue was punished and arrested by police or state secret services. The children in kindergartens and in schools were beaten or punished for speaking their mother tongues at school.

After the democratic changes in Europe in 1990s the situation did not change much in actual fact, despite lip service to being paid to adopting democracy, such as in Bulgaria today (Templer, 2016). The Hungarians in Slovakia, the Roma in many European countries, and the Turks in Germany still face discrimination in society for using their mother tongue, although official documents say that they have the right to study their language and they are free to use it. The author has personally witnessed how kindergarten and primary school teachers forbid the children to use their mother tongue between themselves during class activities or during the free recess time in the playground in several countries around Europe. Many times I have heard teachers saying to Turkish children in Berlin: "Do not speech Turkish! Speak German! This is Germany!" Such attitudes and their reinforcement by school authorities serve to lead to language loss and perhaps an undermining of a solid foundation for such learners to develop literacy to a strong sustained level even in their second language, German.

The results from the research advances several hypotheses about why children appear to begin to 'unlearn' their L1 as they grow somewhat older, and why children in one kindergarten investigated differed in their production competence in Turkish compared to children of the same age in another Berlin-district kindergarten. Also significant is the situation of home language neglect in Berlin, and across most of the US currently, in pre-kindergarten and kindergarten programs, as well as early grades of school. As a 2018 report by the National Institute for Early Education Research (NIEER) at Rutgers University in the US states: "More than 20 percent of all preschool-aged children in the United States speak a language other than English at home, yet most state pre-K programs do not collect data on children's home language, making it nearly impossible to design effective supports for young dual language learners (DLLs)" ${ }^{6}$.

Another factor requiring empirical research not touched on here is access to books in the L1 at home and in libraries in their Berlin localities. To what extent are children reading picture books and other appropriate children's texts in Turkish outside of school? To what extent do school libraries seek to acquire a collection of such books where there are significant proportions of children speaking Turkish as an L1? Empirical research on this is necessary and would probably show significant neglect in Berlin and other German cities. An entirely separate issue whole separate question is communicating with parents of such pupils as key literacy development stakeholders also to involve their children in voluntary reading of picture books, for example, in their home language at an early age and reading such books to them (NIER, 2018).

The research here, although conducted with a limited number of children, shows indirectly a clear tendency in the attitude of the teaching staff in German schools towards the mother tongue of the migrant children. Large numbers of Turkish migrants have been in the German Federal Republic since the 1960s and there is already a third generation, but still the children in kindergartens are not provided with adequate mother-tongue education and a foundation for literacy in their home language. Moreover, there are few in any state initiatives at the pre-k level, as are currently being called for in the US7 (NIER, 2018).

\section{Conclusion}

The research findings showed that the children's knowledge in their mother tongue is not increasing but exactly the opposite - it is decreasing. My hypothesis that the lessons in Turkish that the children get once a week in the kindergartens will help them to increase their knowledge in their L1 Turkish was not proven. Although the kindergarten in Wedding encourages children to speak Turkish, encourages the parents to talk to their children in Turkish in their home environments, to read books and to play using Turkish among themselves with the expectation that it helps the children develop much better knowledge in their mother tongue, still the results of the children from the second testing was not so high.

\footnotetext{
6 Rutgers Today. (2018, May 26). New pre-k report finds state policy for young dual language learners needs improvement. Rutgers Today. Retrieved from https://news.rutgers.edu/new-pre-k-report-finds-state-policy-young-dual-language-learners-needsimprovement/20180418\#.WwzugNR94sY Ibid.
} 
The situation in the kindergarten in Neukölln was markedly different. There the teachers do not allow the children to speak Turkish among themselves and there is no such support as in the kindergarten in Wedding. The results of the children from Neukölln between the two groups showed significant statistical differences. Their knowledge was worse than the knowledge of the children from Wedding.

The research findings are alarming, and action should be taken to preserve the mother tongue among bilingual preschool children because the mother tongue is one of the important tools for cognitive development at an early age. The lack of knowledge of some important grammatical categories in the mother tongue gives later in the preschool difficulties with the literacy process in the primary classes.

The limitations of the study are the small number of the children included in the testing process and the small numbers of test batteries. However, the results still show some important tendencies that should be considered because the phenomenon of language loss among children in early ages is known from scientific literature on other languages.

This study should be repeated with a larger number of Turkish children growing up in different social surroundings - in small towns and in villages. Then perhaps the picture will be fuller and more information about the knowledge of children on their mothertongue grammar will come out.

In order to develop the mother tongue of these children, the kindergartens should increase the lessons to at least four lessons per week. One lesson per week is not enough for the development of the children's knowledge. More training for parents should be done on the importance of speaking and reading books in Turkish in the home environment. The parents should be educated about the importance of the mother tongue in the cognitive development of the children.

From the other side, the teaching staff should be more supportive for children, encouraging them to speak their mother tongue freely in the kindergarten. The policymakers should introduce special lectures about the importance of mother-tongue education in the cognitive development of the child in universities and other institutions preparing preschool teachers.

For the time being all the activities to promote mother-tongue education are private initiatives. The research suggests that not much can be done when relying only on private initiatives. The children begin to "unlearn" their mother tongue already at a fairly young age, likely impacting their cognitive development. So, the question of L1 maintenance and the deepening of solidly grounded literacy therein, both for comprehension and production (spoken and written) remains a question "to be or not to be."

\section{References}

Barac, R., \& Bialystok, E. (2012). Bilingual effects on cognitive and linguistic development: Role of language, cultural background, and education. Child Development, 83(2), 413-422.

Benson, C. J. (2002). Real and potential benefits of bilingual programmes in developing countries. International Journal of Bilingual Education and Bilingualism, 5(6), 303-317.

Becker, B., Klein, O., \& Biedinger, N. (2013). The development of cognitive, language, and cultural skills from age 3 to 6: A comparison between children of Turkish origin and children of nativeborn German parents and the role of immigrant parents' acculturation to the receiving society. American Educational Research Journal, 50(3), 616649. doi:10.3102/0002831213480825

Child, B. J. (1998). Boarding school seasons. Lincoln, NE: University of Nebraska Press.

Cummins, J. (2001). Bilingual children's mother tongue: Why is it important for education? Rights and responsibilities of educators of bilingualbicultural children. In L. D. Soto (Ed.), Making a difference in the lives of bilingual-bicultural learners (pp. 195- 210). New York, NY: Peter Lang.

Cummins, J. (2009). Fundamental psycholinguistic and sociological principles underlying educational success for linguistic minority students. In A. K. Mohanty et al. (Eds.), Multilingual Education for Social Justice: Globalising the Local (pp. 21-35.). New Delhi, India: Orient Black Swan.

de Houwer, A. (2011). Language input environments and language development in bilingual acquisition. Applied Linguistics Review, 2, 221-240.

Dixon, L. Q., Zhao, J., Quiroz, B. G., \& Shin, J.-Y. (2012). Home and community factors influencing bilingual children's ethnic language vocabulary development. International Journal of Bilingualism, 16(4), 541-565. doi:10.1177/1367006911429527.

Giray, B. (2015). Code-switching among Bulgarian Muslim Roma in Berlin. In D. Zeyrek et al. (Eds.), Ankara Papers in Turkish and Turkic Linguistics (pp. 420-430). Wiesbaden, Germany: Harrassowitz Verlag.

Haynes, E. (2010). What is language loss? Heritage Briefs. Washington, DC: Center for Applied Linguistics. Retrieved from: www.cal.org/heritage

Kroll, J., \& Bialystok, E. (2013). Understanding the consequences of bilingualism for language processing and cognition. Journal of Cognitive Psychology, 25(5), 497-514. doi:10.1080/20445911. 2013.799170

MacGregor-Mendoza，P. (2000). Aquí no se habla Español [Spanish is not spoken here]: Stories of 


\section{HRISTO KYUCHUKOV}

linguistic repression in southwest schools. Bilingual Research Journal, 24(4), 333-345.

Malakoff, M., \& Hakuta, K. (1990). History of language minority education in the United States. In A. M. Padilla, H. H. Fairchild \& C. M. Valadez (Eds.), Bilingual education: Issues and strategies (pp. 2743). Newbury Park, CA: Corwin Press, Inc.

Mehmedbegovic, D. (2009). Community and foreign languages. In D. Hill \& L. H. Robertson (Eds.), Equality in the primary school: Promoting good practice across the curriculum (pp. 243-259). London, UK: Continuum.

Mongeau, L. (2018, May 22). Speaking kids' home language in pre-k could provide a lifelong advantage. The Hechinger Report. Retrieved from http://hechingerreport.org/speaking-kids-homelanguage-in-pre-k-could-provide-a-lifelongadvantage/

NIEER. (2018). Special report: Supporting dual language learners in state-funded preschool. In A. H. Friedman-Krauss et al. (Eds.), The State of Preschool 2017, National Institute for Early Education Research (pp. 31-36). Retrieved from http://nieer. org/wp-content/uploads/2018/04/YB2017_DLLSpecial-Report.pdf

Schmitz, A., \& Olfert H. (2013). Minderheitssprachen im Deutschen schulwesen - Eine analyse der implementierung allochthoner und autochthoner sprachen [Minority languages in the German education system - An analysis of the implementation of allochthonous and autochthonous languages]. In Zeitschrift für
Fremdsprachenforschung, 24(2), 203-227.

Skutnabb-Kangas, T. (1995). Multilingualism and the education of minority children. In O. Garcia \& C. Baker (Eds.), Policy and Practice in Bilingual Education: A Reader Extending the Boundaries (pp. 40-62). Clevedon, UK: Multilingual Matters.

Skutnabb-Kangas, T. (2000). Linguistic genocide in education - Or worldwide diversity and human rights? Mahwah, NJ: Lawrence Erlbaum.

Smitherman, G. (1995). Students' right to their own language: A retrospective. The English Journal, 84(1), 21-27.

Templer, B. (2016). Confronting linguicism: Rethinking multiculturalism and bilingual instruction in Bulgarian schools. In H. Kyuchukov (Ed.), New Trends in the Psychology of Language (pp. 143-75). Munich, Germany: Lincom.

Valian, V. (2015). Bilingualism and cognition. Bilingualism: Language and Cognition, 18(1), 3-24. doi:10.1017/S1366728914000522

Yazıc1, Z. (1999). Almanya ve Turkiye'de anaokuluna devam eden 60-76 aylar arasindaki Turk cocuklarının dil Gelișimi ile okuma olgunlug ${ }^{` u}$ arasındakilliskinin Incelenmesi [Investigation of connections between language development and reading readiness of Turkish nursery school children aged 60-76 months in Germany and Turkey] (Unpublished PhD thesis). Gazi University,_Ankara, Turkey.

Yazıcı, Z., İlter, B., \& Glover, P. (2010). How bilingual is bilingual? Mother-tongue proficiency and learning through a second language. International Journal of Early Years Education, 18(3), 259-268. 